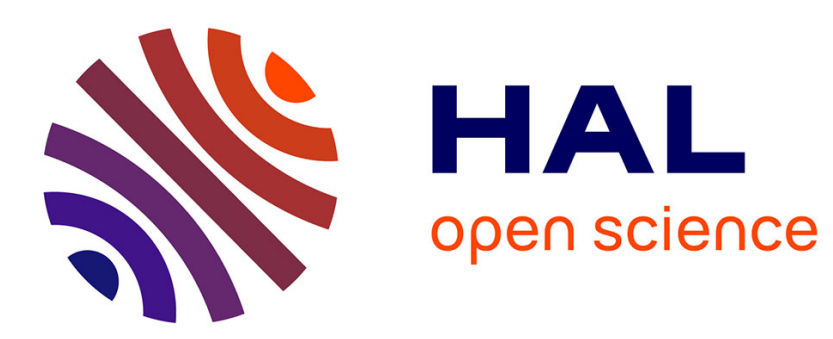

\title{
Investigation into the influence of environmental conditions on power system ratings
}

\author{
Andrea Michiorri, P. C. Taylor, S. C. E. Jupe, C. J. Berry
}

\section{To cite this version:}

Andrea Michiorri, P. C. Taylor, S. C. E. Jupe, C. J. Berry. Investigation into the influence of environmental conditions on power system ratings. Proceedings of the Institution of Mechanical Engineers, Part A: Journal of Power and Energy, 2009, 223 (7), pp.743-757. 10.1243/09576509JPE718 . hal01848969

\section{HAL Id: hal-01848969 \\ https://hal.science/hal-01848969}

Submitted on 25 Jul 2018

HAL is a multi-disciplinary open access archive for the deposit and dissemination of scientific research documents, whether they are published or not. The documents may come from teaching and research institutions in France or abroad, or from public or private research centers.
L'archive ouverte pluridisciplinaire HAL, est destinée au dépôt et à la diffusion de documents scientifiques de niveau recherche, publiés ou non, émanant des établissements d'enseignement et de recherche français ou étrangers, des laboratoires publics ou privés. 


\title{
Investigation into the influence of environmental conditions on
}

\section{power system ratings}

\author{
A. Michiorri ${ }^{1}$, P. C. Taylor ${ }^{2}$, S. C. E. Jupe ${ }^{3}$, C. J. Berry ${ }^{4}$ \\ ${ }^{1,2,3}$ School of Engineering, Durham University, South Road, Durham, DH1 3LE \\ ${ }^{3}$ SP Power Systems, 3 Prenton Way, Birkenhead, CH43 3ET \\ 1 andrea.michiorri@durham.ac.uk \\ ${ }^{2}$ p.c.taylor@durham.ac.uk \\ ${ }^{3}$ s.c.e.jupe@durham.ac.uk \\ ${ }^{4}$ chris.berry@sppowersystems.com
}




\section{Abstract}

This paper presents research which seeks to assist distribution network operators in the adoption of real-time thermal rating systems. The exploitation of power system rating variations is challenging due to the complex nature of environmental conditions such as wind speed. The adoption of a realtime thermal rating system may overcome this challenge and offers perceived benefits such as increased distributed generation accommodation and avoidance of component damage or premature ageing. Simulations, using lumped parameter component models, are used to investigate the influence of environmental conditions on overhead line, electric cable and power transformer ratings. Key findings showed that the average rating of overhead lines, electric cables and power transformers ranged from 1.70 to $2.53,1.00$ to 1.06 and 1.06 to 1.10 times the static rating, respectively. Since overhead lines were found to have the greatest potential for rating exploitation, the influence of environmental conditions on four overhead line types was investigated and it was shown that the value of a real-time thermal rating system is location dependent. Furthermore, the additional annual energy yield from distributed generation that could be accommodated through a real-time thermal rating system deployment was quantified for a specific case and found to be $54 \%$. 


\section{Introduction}

This paper describes the offline simulation of power system thermal models populated with historical environmental conditions in order to derive real-time thermal ratings (RTRs). This information is used to quantify (in GWhs) the exploitable headroom that may be achieved by implementing an RTR system within distribution networks. In many cases the current carrying capacity of power system components is limited by a maximum allowable operating temperature. Actual component operating temperatures are determined by the ability of components to dissipate to the environment the heat produced by the Joule effect and by environmental conditions such as ambient temperature and wind speed, which are continuously varying. As a result, the current carrying capacity of components may be continually assessed and this is proportional to the RTR in MVA. For the purpose of this research, RTRs are defined as a time-variant rating which can be practically exploited without damaging components or reducing their life expectancy. Actual measurements of environmental conditions are used as the input to steady-state thermal models. In order to calculate and exploit the RTR, it is assumed that local environmental condition measurements are available and that there are no outages (planned or unplanned) present within the electrical power system. Short term transients, taking into account the thermal capacitance of power system components, are not included within the RTR assessment. It is felt that this would not materially affect the GWh/annum throughput of energy within the electrical power system. The mechanisms of heat exchange underpinning component ratings are well-documented [1-3]. However, the estimation of component operating temperatures (and thus current carrying limits) is a non-trivial task. This is because of the complexity of monitoring and modelling environmental conditions. For this reason component ratings based on fixed assumptions of environmental conditions are often used by distribution network operators (DNOs). The implementation of a RTR system has the potential to give DNOs greater visibility of network operating conditions thus 
reducing the risk of exceeding the component maximum operating temperature. This could be used both offline, to inform power system planning, and online, within future operational philosophies, in order to increase cautiously the utilisation of power system components. However, system implementation requires a number of challenges to be overcome, including the measurement, estimation and communication of real-time component temperatures and environmental conditions. At the distribution network level these are likely to be dispersed over complex terrains throughout wide geographical areas containing significant numbers of power system components. The research described in this paper forms part of a UK Government part-funded project [4] which aims to develop and deploy an online power output controller for distributed generation (DG) based on component RTRs. In this project a DG power output controller compares RTRs with network power flows and produces set points that are fed back to the DG operator for implementation, as shown in Figure 1. The research consortium includes ScottishPower EnergyNetworks, AREVA T\&D, PB Power, Imass and Durham University.

The paper is structured in the following way: Section 2 provides an overview of relevant work. In Section 3, the models developed for network components and environmental conditions are described. Section 4 describes the component data, the environmental condition data and the RTR simulation approach and in Section 5 simulation results are presented and discussed. 


\section{Relevant work}

Significant research has been carried out at the transmission level for RTR applications. Research tends to focus on overhead lines which, due to their exposure to the environment, exhibit the greatest rating variability. A description of the cost and suitability of different uprating techniques for overhead lines is described in [5], taking into account different operating conditions. This work shows how RTRs can be a more appropriate solution than network reinforcement when connecting new customers to the network who are able to curtail their generation output or reduce their power demand requirement at short notice. Similarly, experience regarding thermal uprating in the UK is reported in [6] where it was suggested that RTRs could give overhead lines an average uprating of $5 \%$ for $50 \%$ of the year. An example of an RTR application for transmission overhead lines of Red Eléctrica de España, is described in [7] where a minimal amount of weather stations are used to gather real-time data. The data is then processed using a meteorological model based on the Wind Atlas Analysis and Application Program (WAsP) [8], taking into account the effect of obstacles and ground roughness, and finally the rating is calculated. A similar system was developed in the USA by EPRI in the late 1990s which considered overhead lines, power transformers, electric cables and substation equipment. The system is described in [9] and preliminary results of field tests are given in [10]. A key finding was that up to 12 hours of low wind speeds $(<0.76 \mathrm{~m} / \mathrm{s})$ were observed during the field tests which therefore suggests that overhead line RTRs may be lower than seasonal ratings for extended periods of time. Furthermore, a strong correlation was found to exist between independent air temperature measurements distributed along the lengths of the overhead lines. At the distribution level, an RTR project carried out by the Dutch companies NUON and KEMA is described in [11] which demonstrates the operating temperature monitoring of overhead lines, electric cables and power transformers. 
The advantages of an RTR system for the connection of DG, especially wind power, are reported in various sources, each of which considers only single power system components. It is demonstrated in [12] that the rating of transformers positioned at the base of wind turbines may presently be oversized by up to $20 \%$. Moreover, in [13] the power flowing in an overhead line close to a wind farm is compared to its RTR using WAsP [8]. In this research it was highlighted that high power flows resulting from wind generation at high wind speeds could be accommodated since the same wind speed has a positive effect on the line cooling. This observation makes the adoption of RTR systems relevant in applications where strong correlations exist between the cooling effect of environmental conditions and electrical power flow transfers. Moreover, in [14-16] the influence of component thermal model input errors on the accuracy of RTR systems is studied. The application of different state estimation techniques, such as affine arithmetic, interval arithmetic and Montecarlo simulations was studied for overhead lines, electric cables and power transformers. An error band of up to $30^{\circ} \mathrm{C}, 35^{\circ} \mathrm{C}$ and $20^{\circ} \mathrm{C}$ was found when estimating the operating temperature of overhead lines, electric cables and power transformers respectively. This highlights the necessity to have reliable and accurate environmental condition monitoring.

The thermal models, used to estimate RTRs for different types of power system components, are fundamental to this research as the accuracy of the models influence significantly the accuracy of RTRs obtained. Particular attention was given to industrial standards because of their wide application and validation both in industry and academia. For overhead lines, the model is described in $[17,18]$ which has been developed into industrial standards $[1,19,20]$ by the IEC, CIGRE and IEEE respectively. Static seasonal ratings for different standard conductors and for calculated risks are provided by the Electricity Network Association (ENA) in [21]. Thermal model calculation methods for electric cable ratings are described in [22] and developed into an industrial standard by the IEC in [2]. The same models are used by the IEEE in [23] and the ENA in [24] to produce tables of calculated ratings for particular operating conditions. Power transformer thermal behaviour is 
described in [25] with further models described in the industrial standards $[3,26,27]$ by the IEC, IEEE and ENA respectively.

The research presented in this paper adds to the work described above by modelling the influence of environmental conditions on multiple power system component types simultaneously. This is of particular relevance in situations where the increased power flow resulting from the alleviation of the thermal constraint on one power system component may cause an entirely different component to constrain power flows. Furthermore, with the expected proliferation of DG the resulting power flows are likely to affect many components and it is important to take a holistic view of power system thermal ratings. Since this research project aims to develop and deploy an economically viable real-time system, it is important that algorithms are developed with fast computational speeds using a minimal amount of environmental condition monitoring. Thus an inverse distance interpolation technique is used for modelling environmental conditions across a wide geographical area, which offers faster computational speeds than applications such as WAsP. Beyond the research described above this paper also aims to quantify the annual energy throughput that may be gained through the deployment of an RTR system. 


\section{Modelling approach}

\subsection{Components}

In order to assess, in a consistent manner, component RTRs due to the influence of environmental conditions, thermal models were developed based on IEC standards [16, 21, 25] for overhead lines, electric cables and power transformers respectively. Where necessary, refinements were made to the models using $[17,23]$. Steady-state models have been used in preference to dynamic models since this would provide a maximum allowable rating for long term power system operation. Moreover, the estimation of final steady-state component temperatures after a transient has occurred is influenced by initial conditions which must also be estimated. It is felt that with the resolution of the available data (comprising hourly averaged environmental conditions) it is extremely difficult to obtain an acceptable precision for dynamic models, particularly for overhead lines with time constants of less than an hour.

\subsubsection{Overhead lines}

Overhead line ratings are constrained by a necessity to maintain statutory clearances between the conductor and other objects. The temperature rise causes conductor elongation which, in turn, causes an increase in sag. The line sag $(S)$ depends on the tension $(H)$, the weight $(m)$ applied to the conductor inclusive of the dynamic force of the wind and the length of the span. The sag can be calculated as a catenary or its parabolic approximation, as given in Equation (1). To calculate the tension, it is necessary to consider the thermal-tensional equilibrium of the conductor, as shown in Equation (2). For calculating the conductor operating temperature at a given current, or the maximum current for a given operating temperature, it is necessary to solve the energy balance between the heat dissipated in the conductor by the current, and the thermal exchange on its surface, as given in Equation (3). 


$$
\begin{gathered}
S=\frac{H}{m g}\left[\cosh \left(\frac{m g L}{2 H}\right)-1\right] \approx \frac{m g L^{2}}{8 H} \\
E A \beta\left(T_{c, 2}-T_{c, 1}\right)+\left(\frac{m_{1}^{2} g^{2} L^{2} E A}{24 H_{1}^{2}}\right)-H_{1}=\left(\frac{m_{2}^{2} g^{2} L^{2} E A}{24 H_{2}^{2}}\right)-H_{2} \\
q_{c}+q_{r}=q_{s}+r I^{2}
\end{gathered}
$$

The formulae proposed in [16] were used for the calculation of the contribution of solar radiation $\left(q_{s}\right)$, radiative heat exchange $\left(q_{r}\right)$ and convective heat exchange $\left(q_{c}\right)$. These equations are shown in Equations (4)-(6) respectively.

$$
\begin{gathered}
q_{s}=\alpha D W_{s} \\
q_{r}=\varepsilon \sigma_{S-B}\left(T_{c}^{4}-T_{a}^{4}\right) \pi D \\
q_{c}=\pi N u \lambda\left(T_{c}-T_{a}\right)
\end{gathered}
$$

Natural convection and the influence of wind direction on forced convection are not considered in [16]. However, in this research these effects were considered to be important so the modification proposed in [17] and given in Equations (7) and (10) were used. It is possible to calculate the Nusselt number $(\mathrm{Nu})$ from the Reynolds number $(\mathrm{Re})$ as shown in Equation (8). The Reynolds number can be calculated using Equation (9).

$$
\begin{gathered}
K_{d i r}=K_{d i r-1}+K_{d i r-2} \sin ^{K_{d i r-3}} \delta \\
N u=K_{d i r} \cdot\left(0.65 \cdot \mathrm{Re}^{0.2}+0.23 \cdot \mathrm{Re}^{0.61}\right) \\
\operatorname{Re}=1.644 \cdot 10^{9} \cdot w_{s} D\left(\frac{T_{c}+T_{a}}{2}\right)^{-1.78}
\end{gathered}
$$

For null wind speeds, the Nusselt number must be calculated as in Equation (10) where $G r$ is the Grashof number, calculated as in Equation (11), and Pr is the Prandtl number.

$$
N u=K_{n a t-1}(G r \cdot \operatorname{Pr})^{K_{n a t-2}}
$$




$$
G r=\frac{D^{3}\left(T_{c}-T_{a}\right) \cdot g}{\frac{\left(T_{c}+T_{a}\right)}{2} \cdot v^{2}}
$$

It should be noted that for wind speeds between $0-0.5 \mathrm{~m} / \mathrm{s}$ the larger of the Nusselt numbers resulting from Equation (8) and (10) should be used.

\subsection{2. $\quad$ Electric cables}

The current carrying capacity of electric cables is limited by the maximum operating temperature of the insulation. Sustained high currents may generate temperatures in exceedance of the maximum operating temperature, causing irreversible damage to the cable. In extreme cases this may result in complete insulation deterioration and cable destruction.

References [21, 23] were used to model the conductor temperature in steady-state conditions. This accounts for the heat balance between the power dissipated in the conductor by the Joule effect, and the heat dissipated in the environment through the thermal resistance $\left(R_{T}\right)$ of the insulation and the soil as shown in Equation (12). The electrical current rating may then be calculated, as shown in Equation (13).

$$
\begin{gathered}
I^{2} r=\Delta T / R_{T} \\
I=\sqrt{\frac{\Delta T}{r \cdot R_{T}}}
\end{gathered}
$$

Refinements incorporating dielectric losses $\left(q_{d}\right)$, eddy currents and circulating currents in metallic sheaths $\left(\lambda_{1,2}\right)$, resistance variation with temperature, skin and proximity effects and the thermal resistance of each insulating layer $\left(R_{T, i}\right)$ lead to the more complex Equation (14).

$$
I=\sqrt{\frac{\Delta T-q_{d}\left[1 / 2 R_{T, 1}+n\left(R_{T, 2}+R_{T, 3}+R_{T, 4}\right)\right]}{r\left(T_{c}\right)\left[R_{T, 1}+n\left(1+\lambda_{1}\right) R_{T, 2}+n\left(1+\lambda_{1}+\lambda_{2}\right)\left(R_{T, 3}+R_{T, 4}\right)\right]}}
$$

Thermal resistances for cylindrical layers are calculated with Equation (15) and soil thermal resistance is modelled with Equation (16). Other calculation methods [21] have to be utilised when 
operating conditions differ from those stated above (for example when the cable is in a duct or in open air).

$$
\begin{gathered}
R_{T, 1-2-3}=\frac{\rho_{T}}{2 \pi} \ln \left(1+2 \frac{D-d}{d}\right) \\
R_{T, 4}=\frac{\rho_{T}}{2 \pi} \ln \left(\frac{2 z_{b}}{D}+\sqrt{\left(\frac{2 z_{b}}{D}\right)^{2}+1}\right)
\end{gathered}
$$

The model described above requires detailed knowledge of the electric cable installation. However, this information may not always be available and therefore it is difficult to make practical use of the model. In these circumstances an alternative model, described in [23] and summarised in Equation (17), may be used. The current rating $\left(I_{0}\right)$ is given in tables depending on the standardised cable cross-sectional area and laying conditions (trefoil, flat formation; in air, in ducts or direct buried). The dependence on external temperature $\left(\xi_{T}\right)$ and soil thermal resistivity $\left(\xi_{\rho}\right)$ is made linear.

$$
I=I_{0}(A, V, \text { laying }) \cdot\left[\xi_{T} \cdot\left(T_{S}-T_{S, \text { rated }}\right)\right] \cdot\left[\xi_{\rho} \cdot\left(\rho_{T}-\rho_{T, \text { rated }}\right)\right]
$$

Since this research concerns the influence of environmental conditions on component ratings, the effect of the voltage level (V), which influences the dielectric loss $\left(q_{d}\right)$ in Equation. (14) is not considered. The effect of the heating given by adjacent components is also neglected as it is assumed that each cable has already been de-rated to take this effect into account.

\subsubsection{Power transformers}

The model described in [25] was used to calculate the winding hot spot temperature for power transformers. This is the most important parameter since hotspot temperature exceedance can damage the transformer in two ways. Firstly, a temperature exceedance of $120^{\circ} \mathrm{C}-140^{\circ} \mathrm{C}$ can induce the formation of bubbles in the coolant oil, which in turn is liable to cause an insulation breakdown due to the local reduction of dielectric insulation strength. Secondly, high temperatures increase the ageing rate of the winding insulation. For this reason the maximum operating temperature should 
not exceed the rated value. The thermal model consists of a heat balance between the power dissipated in the winding and iron core, and the heat transferred to the environment via the refrigerating circuit. Considering the thermal resistance between the winding and the oil $\left(R_{T, W}\right)$, the thermal resistance between the heat exchanger and the air $\left(R_{T, H E}\right)$ and the power dissipated into the core $\left(I^{2} r_{\text {windings }}\right)$, it is possible to calculate the hot spot temperature $\left(T_{H S}\right)$ as in Equation (18).

$$
T_{H S}=T_{a}+I^{2} r_{\text {windings }} \cdot\left(R_{T, W}+R_{T, H E}\right)
$$

Equation (16) is discussed in [24] leading to the IEC standard model for rating oil-filled power transformers as shown in Equation (19).

$$
T_{H S}=T_{a}+\left(T_{T O}-T_{a}\right)\left(\frac{1+R K^{2}}{1+R}\right)^{x}+\left(T_{H S}-T_{T O}\right) K^{y}
$$

The maximum rating can be obtained by iteration, once the hot spot temperature has been set, and tabulated values for the parameters can be found in [25] for transformers with different types cooling system. Correction factors in [26] can be used to model other operating conditions such as transformers operating within enclosures.

\subsection{Environmental conditions}

This section describes the approach adopted to estimate, correct and interpolate environmental conditions to represent more accurately the actual environmental operating conditions for sections of the UK power system in different geographical areas.

\subsubsection{Environmental condition interpolation}

The inverse distance interpolation technique [28] allows environmental conditions to be determined over a wide geographical area using a reduced set of inputs. This is attractive for situations where a large amount of installed measurements may be financially unattractive to the DNO. The technique is also computationally efficient and allows the input locations to be readily adapted. The wind speed correction process is described in Section 3.2.2. The soil parameter correction process is 
described in Section 3.2.3. Wind direction, air temperature and solar radiation values were included within interpolations but did not require the application of a correction factor. At each point in the geographical area $(k)$ the value of the parameter $(Z)$ representing the environmental condition can be estimated as a weighted average of the parameter values known at $i$ points. The weighting factor is a function of the distance between the points as shown in Equation (20).

$$
Z_{k}=\frac{\sum_{i} \frac{1}{d_{i, k}^{2}} Z_{i}}{\sum_{i} \frac{1}{d_{i, k}^{2}}}
$$

\subsubsection{Wind speed correction}

Ground roughness influences wind speed profiles and may lead to differences between the wind speed recorded by anemometers and the actual wind speed passing across an overhead line, particularly if the anemometer and overhead line are installed at different heights. This may be corrected using the wind profile power law given in Equation (21). The wind speed at two different heights $\left(z_{1}\right.$ and $\left.z_{2}\right)$ is linked with the ground roughness through the exponent $K_{\text {shear }}$. Values of $K_{\text {shear }}$ for different ground types may be found in [28].

$$
w_{s}\left(z_{1}\right)=w_{s}\left(z_{2}\right) \cdot\left(\frac{z_{1}}{z_{2}}\right)^{K_{\text {shear }}}
$$

Using Equation (21), the anemometer wind speed is extrapolated to a reference height (in this case 100 metres) to remove ground roughness dependence. The values from different anemometer locations may then be interpolated, using Equation (20) as described in Section 3.2.1, to provide a wind speed estimate at the reference height for a particular geographical location. The ground roughness at this location is then taken into account and Equation (21) is used to estimate the wind speed across the overhead line. 


\subsubsection{Soil parameter estimation}

Electric cable ratings are dependent on soil temperature and soil thermal resistivity, as well as cable construction, burial layout and burial depth (which is typically $0.8-1$ metre). MetOffice [30] datasets contain information regarding soil temperatures at a depth of 0.3 metres. However, no information was available from this source regarding soil thermal resistivity. Depth-dependent soil temperature distributions may be calculated using the Fourier law [31] as shown in Equation (22).

$$
\frac{d T_{s}}{d t}=\frac{d}{d z}\left(\delta_{s-T}(\theta) \frac{d T_{s}}{d z}\right)
$$

Boundary conditions were set up with a constant temperature of $10^{\circ} \mathrm{C}$ at a depth of 2 metres for the lower layer and MetOffice soil temperature readings for the upper layer. Soil thermal resistivity $\left(\rho_{s-}\right.$ $T$ ), may be calculated from Equation (23) using the soil thermal diffusivity $\left(\delta_{s-T}\right)$, the dry soil density $\left(\rho_{s-d e n s i t y}\right)$, and the soil thermal capacity $\left(C_{s-T}\right)$.

$$
\rho_{s-T}=\left(\delta_{s-T} \cdot \rho_{s-d e n s i t y} \cdot C_{s-T}\right)^{-1}
$$

Soil thermal diffusivity $\left(\delta_{s-T}\right)$ and soil thermal capacity are influenced by soil composition $(\mathrm{N})$ and water content $(\theta)$ and can be calculated using Equation (24) and (25) [32].

$$
\begin{gathered}
\delta_{s-T}(\theta)=-14.8+0.209 \cdot N+4.79 \cdot \theta \\
C_{s-T}=-0.224-0.00561 \cdot N+0.753 \cdot \rho_{s-\text { density }}+5.81 \cdot \theta
\end{gathered}
$$

Ground water content may be determined using the closed form of Richard's equation [33] as described in Equation (26) after the calculation of the unsaturated hydraulic diffusivity $\left(\delta_{\mathrm{s}-} \theta(\theta)\right)$ and the unsaturated hydraulic conductivity $\left(k_{\mathrm{s}-\theta}(\theta)\right)$ as described in [34].

$$
\frac{d \theta}{d t}=\frac{d}{d z}\left[\delta_{s-\theta}(\theta) \frac{d \theta}{d z}+k_{s-\theta}(\theta)\right]
$$

In order to solve Equation (26), boundary and initial conditions must be specified. A constant water content equal to the saturation value was set at a depth of 2.5 metres, corresponding to the water 
table. Furthermore, the ground-level water content was linked to MetOffice rainfall values $\left(l_{r}\right)$ using the model described in Equation (27), where $K_{\text {rain, } 1}$ and $K_{\text {rain, }, 2}$ can be calculated using [35].

$$
\frac{d \theta}{d t}=-K_{\text {rain }, 1} \cdot \theta(t)+K_{\text {rain }, 2} \cdot l_{r}(t)
$$




\section{Simulation approach}

In Figure 2, a general description of the simulation algorithm, with the different software applications, is provided. The algorithm uses three databases to store network component data, weather measurement data and calculated rating data respectively. It comprises two main applications: the environmental condition processor (ECP) for simulating weather data, described in Section 3.2 and the component thermal models (CTM) for calculating component ratings, as described in Section 3.1. A third application (Coordination) was added to supervise the simulation dataflow.

\subsection{Weather}

MetOffice datasets were used, referring to four British airports: Bishopton (Glasgow), Valley (Anglesey), Woodford (Manchester) and Heathrow (London) [30]. The data comprised hourly averages of wind speed, wind direction, air temperature, solar radiation and soil temperature throughout the calendar year 2005. In Figures 3-5, the data from those sites is summarised and compared.

In Figure 3 it is possible to observe the different site characteristics for the wind speed: Valley, on the west coast of Wales, is the windiest area with the highest maximum wind speed values and a probability distribution (P.D.) with the smallest peak. Heathrow, which is located in an urban environment, has wind speeds that are generally lower and more concentrated in the range between 2-7m/s. As seen in Figure 4, air temperature appears to be the least variable parameter. Different sites may be differentiated by average temperature values. In Figure 5, the behaviour of the soil temperature is illustrated. Whereas the air temperature shows a variation with one peak across the year, soil temperature appears to vary with multiple peaks.

Regarding wind direction, the presence of prevalent winds from the West and the North-West in the range $180^{\circ}-360^{\circ}$ was noted for all areas. Some areas also exhibited site-specific prevalent wind 
directions, for example from the South-West in Woodford and from North-North-West in Bishopton. Regarding solar radiation, no significant differences between the four sites were found.

\subsection{Networks}

In order to simulate in a rigorous manner the influence of environmental conditions on power system ratings, three network models were adapted from the United Kingdom Generic Distribution Systems (UKGDSs) [36], each of which contain the three component types considered in this paper. Moreover, a portion of the ScottishPower EnergyNetworks distribution network was included in simulations as this will be instrumented in the near future for RTR validation purposes. Voltage levels in the four networks studied vary from $6.6 \mathrm{kV}$ to $132 \mathrm{kV}$.

The ScottishPower EnergyNetworks Site network is shown in Figure 6 and has a meshed topology, with a prevalence of Lynx $175 \mathrm{~mm}^{2}$ overhead lines. The network also has eleven electric cable circuits of $150 \mathrm{~mm}^{2}$ at the $33 \mathrm{kV}$ level and thirteen power transformers rated at $45 \mathrm{MVA}, 60 \mathrm{MVA}$, 90MVA and 240MVA. Topological representations of the UKGDSs can be found in Appendix 7.3. Technical characteristics for the overhead lines may be found in [19]. UKGDS A has six overhead line circuits with Zebra and Lynx conductors rated at $50^{\circ} \mathrm{C}, 65^{\circ} \mathrm{C}$ and $75^{\circ} \mathrm{C}$, twelve electric cables circuits with $150 \mathrm{~mm}^{2}$ and $240 \mathrm{~mm}^{2}$ conductors, and sixteen transformers with ratings from 14MVA to 500MVA. UKGDS B consists of six overhead lines with Zebra and Lynx conductors, eight electric cable circuits with $150 \mathrm{~mm}^{2}$ conductors and thirteen power transformers, with ratings from of 21MVA and 500MVA. UKGDS $\mathrm{C}$ is characterized by a prevalence of electric cable circuits and power transformers. It comprises two overhead lines with Zebra conductors, twelve electric cable circuits with $150 \mathrm{~mm}^{2}$ and $240 \mathrm{~mm}^{2}$ conductors and eighteen power transformers with ratings from 14MVA to 500MVA. Electrical parameters for modelling the UKGDSs may be found in [36]. 


\section{Results and analysis}

In order to quantify the influence of environmental conditions on power system ratings, simulations were carried out on the networks described in Section 4.2 subjected to a range of UK climatic conditions. For each scenario the minimum, maximum and average rating values together with additional potential annual energy throughput (in GWh) were calculated and the results are tabulated in Appendix 7.3. This data may be summarised as follows: The average rating of overhead lines ranged from 1.70 to 2.53 times the static rating with minimum and maximum ratings of 0.81 and 4.23 respectively. The average rating of electric cables ranged from 1.00 to 1.06 times the static rating with minimum and maximum ratings of 0.88 and 1.23 respectively. The average rating of power transformers ranged from 1.06 to 1.10 times the static rating with minimum and maximum ratings of 0.92 and 1.22 respectively.

Simulations results were analysed in three different ways: (i) comparing the rating cumulative probabilities of different component types against one another within the same network and environmental conditions, (ii) comparing the GWh headroom of four different overhead line types subjected to four different UK climates and (iii) assessing the increased energy throughput from DG that may be accommodated by using RTRs, as opposed to seasonal ratings, for a single overhead line.

\subsection{Rating comparison of different component types}

In Table 1, the simulation results for the Site network exposed to the Valley climatic scenario are given. For each component type the average, minimum and maximum RTR is given, and the additional headroom theoretically obtainable with RTRs (as opposed to seasonal ratings) is quantified. The additional headroom was calculated by summing the difference between the RTR and the seasonal ratings across the year in hourly intervals. For overhead lines, the seasonal ratings reported in [18] were used for this calculation. In Figure 7a, the rating cumulative probabilities for 
the four components described in Table 1 are shown. RTRs have been normalized using the static component rating. From inspection of Figure 7a it is evident that overhead lines show the greatest potential for rating exploitation. As seen in Figure $7 \mathrm{~b}$, electric cable and power transformer ratings have a limited variability. This is because soil temperature, soil thermal resistivity and air temperature are much less variable than wind speed and direction and it is these latter parameters which greatly influence the rating of overhead lines. This is in agreement with the analysis in Section 4.1. By representing component ratings as cumulative probabilities, the potential comparison with power transfer duty (PTD) curves is facilitated. Moreover, distribution network operators are able to specify a probability with which they are comfortable to operate a particular component and an assessment of the corresponding rating may be made.

\subsection{Rating comparison of overhead line types}

It was shown in Figure 7 and Table 1 that overhead lines exhibit the greatest potential for RTR exploitation. Therefore, in Figure 8 the average headroom for different overhead line types, exposed to different climatic scenarios, is compared. For each case, the average headroom is given along with the minimum and maximum headroom. Headroom variations exist since differences in component orientation and component location result in rating variations. Variation bars are representative of the possible headroom ranges simulated. The size of the variation band is determined by the number of components existing within each case study network. A large variation band represents a frequently occurring component. By inspecting the position of the lower variation band it is evident that the additional headroom is greater for conductors with a greater initial static rating, and this effect is accentuated by conductor rated temperature. This is because the conductor temperature rise above ambient temperature multiplies the heat exchange coefficient as seen in Equation (6). 
Regarding the influence of the climates, Valley exhibits the highest average wind speed values and Bishopton the lowest average temperatures as seen in Figures 3 and 4. Since overhead line ratings are more sensitive to wind speed than air temperature the climate of Valley leads to the greatest overhead line power transfer headroom. Clearly from this evidence the value of adopting an RTR system is dependent on geographical location. Therefore any utility interested in deploying an RTR system should conduct a site specific study to assess the value of RTRs as the output varies according to climate, and therefore the economic value is different. Furthermore, the quantification assessment presented in Figure 8 allows a conservative approach to be adopted in developing RTR systems since an investor may choose to utilise the rating seen at the bottom of the variation band.

\subsection{Power transfer accommodation assessment}

This section presents a methodology for quantifying the practically exploitable headroom for the specific case of a $132 \mathrm{kV}$ Lynx overhead line conductor with a maximum operating temperature of $50^{\circ} \mathrm{C}$ subjected to the Valley climate in the Site network. This location was selected since it is an area attractive to prospective wind farm development. The practically exploitable headroom was quantified as follows: Meteorological wind data from the Valley site was used together with the GE 3.6MW wind turbine power curve [38] to assess the power generated throughout the year and transferred through the overhead line conductor. By comparing the power transfer across the year with the overhead line rating, for both seasonal and RTR regimes, the wind farm installed capacity was sized to correspond to a line cumulative overload probability of $1 / 1000$ (8.76 hours/annum). Results are summarized in Figure 9, where the line RTR cumulative probability, along with the inverse cumulative probability for two different PTDs, seasonal and switchgear ratings are represented. The cumulative probability curve (the RTR distribution) may be interpreted by selecting an acceptable probability at which the component may be operated, for example 0.1 (10\%). This corresponds to a rating of 149MVA. Therefore there is the probability of $10 \%$ that 
during the course of the year the rating is less than or equal to 149MVA (conversely there is a $90 \%$ probability that the rating is greater than 149MVA). Similarly the inverse cumulative probability (PTD curves 1 and 2) may be interpreted by selecting a power transfer duty value, for example 76MVA on PTD 2 curve. This corresponds to a probability of $10 \%$. Therefore there is a probability of $10 \%$ that during the course of the year PTD 2 is greater than or equal to 76MVA (conversely there is a $90 \%$ probability that the PTD is less than 76MVA). For the seasonal rating regime an installed capacity of $89 \mathrm{MW}$ could be accommodated and an annual energy yield from the wind farm of $245 \mathrm{GWh}$ could be attained. For the RTR regime, an installed capacity of $137 \mathrm{MW}$ could be accommodated and an annual energy yield from the wind farm of $377 \mathrm{GWh}$ could be attained. This represents a percentage increase of $54 \%$ which could be achieved through the development and deployment of a RTR system. Furthermore, from Figure 8, it can be seen that a theoretical headroom range exists due to different site characteristics. In this case the practically exploitable headroom represents an increase of $10 \%$ above the average exploitable headroom.

An estimation of the losses associated with the two PTD curves was carried out in the following way: From the average environmental conditions at the Valley site and from the average value of the power transfer, the average conductor temperature was calculated. From this, the average conductor resistance was calculated and, using the hourly values of the power transfer, it was possible to obtain the losses arising from Joule effect for the whole year. Loss values of $0.12 \%$ and 0.19\% of the entire annual energy throughput were obtained for PTD 1 and PTD 2 respectively. 


\section{Conclusion}

This paper described the offline simulation of power system thermal models populated with historical environmental conditions in order to derive RTRs. This information was used to quantify (in GWhs) the exploitable headroom that may be achieved by implementing an RTR system within distribution networks. Power system component models were developed based on IEC standards and environmental conditions were corrected and interpolated to represent, as closely as possible, actual network operating conditions. Component data and environmental condition data were used to populate the models in simulation to derive component RTRs. For a wide number of power system components and environmental conditions the minimum, maximum and average ratings were quantified together with the additional power transfer headroom. This information is likely to be of use to DNOs in planning and operating future distribution networks that may be reaching a level of power transfer saturation. It was found that overhead lines exhibit the greatest potential RTR exploitation since they exhibit the greatest rating variability. Furthermore, it was found that power transformers and electric cables have a slight RTR exploitation potential relative to overhead lines. The value of adopting an RTR system is dependent on geographical location. Therefore any utility interested in deploying an RTR system should conduct a site specific study to assess the value of RTRs as the output varies according to climate, and therefore the economic value is different.

The increase in power transfer from DG that could be accommodated through a real-time thermal rating system implementation was investigated. For a Lynx overhead line conductor with a maximum operating temperature of $50^{\circ} \mathrm{C}$ it was found that a $\mathrm{GWh}$ energy throughput increase of $54 \%$ could be accommodated by operating the line with a RTR regime as opposed to a seasonal rating regime. Work is continuing in this area to realise the potential of RTR system implementations. 


\section{Acknowledgments}

The authors wish to acknowledge the Department for Innovation, Universities and Skills for

funding, and the staff from AREVA T\&D, Imass, PB Power, ScottishPower Energy Networks and the MetOffice for their valuable input to this work. 


\section{References}

1 IEC TR 1597, Overhead electrical conductors - calculation methods for stranded bare conductors

2 IEC 60287, Electric cables - calculation of the current rating, 1994

3 IEC 60076-7 Power transformers - Part 7: Loading guide for oil-immersed power transformers, 2008

4 Neumann, A., Taylor, P., Jupe, S., Michiorri, A., Goode, A., Curry, D. and Roberts, D: Dynamic thermal rating and active control for improved distribution network utilisation. PowerGrid 08, Milan, Italy, 2008

5 Stephen, R. Description and evaluation of options relating to uprating of overhead transmission lines, Electra, B2-201, 2004

6 Hoffmann, S. P., Clark, A. M. The approach to thermal uprating of transmission lines in the UK, Electra, B2-317, 2004

7 Soto, F., Latorre, J., Wagensberg, M. Increasing the capacity of overhead lines in the 400 kV Spanish transmission network: real time thermal ratings, Electra 22-211, 1998

$8 \quad$ http://www.wasp.dk, accessed January 2008

9 Douglass, D. A., Edris A. A. Real-time monitoring and dynamic thermal rating of power transmission circuits, IEEE Transactions on Power Delivery, 1996, 11(3), 1407-1418

10 Douglass D. A., Edris A. A., Pritchard G. A. Field application of a dynamic thermal circuit rating method, IEEE Transactions on Power Delivery, 1997, 12 (2), 823-831

11 Nuijten, J. M. A., Geschiere, A. Future network planning and grid control, International Conference on Future Power Systems, Amsterdam, Netherlands, Nov 16-18, 2005

12 Helmer, M. Optimized size of wind power plant transformer and parallel operation, Wind Power for the 21st century, Kassel, Germany, 25-27 Sep., 2000 
13 Belben, P. D., Ziesler, C. D. Aeolian uprating: how wind farms can solve their own transmission problems, World Wind Energy Conference and Exhibition, Berlin, Jul 2002

14 Piccolo, A., Vaccaro, A., Villacci, D. Thermal rating assessment of overhead lines by Affine Arithmetic, Electric Power Systems Research, 2004, 71(3), 275-283

15 Villacci, D., Vaccaro, A. Transient tolerance analysis of power cables thermal dynamic by interval mathematic, Electric Power Systems Research, 2007, 77 308-314

16 Ippolito, L., Vaccaro, A., Villacci, D. The use of affine arithmetic for thermal state estimation of substation distribution transformers, COMPEL: The International Journal for Computation and Mathematics in Electrical and Electronic Engineering, 2004, 23(1), 237 249

17 House, H. E., Tuttle, P. D. Current Carrying Capacity of ACSR. IEEE Transactions on Power Apparatus Systems, 1959, 78(3) 1169-1177.

18 Morgan, V.T. The thermal rating of overhead-line conductors. 1. The steady-state thermal mode, Electric Power Systems Research, 1982. 5(2) 119-139.

19 WG 22.12, The Thermal Behaviour of Overhead Conductors - Section 1. Electra, 1992 144(3)

20 IEEE 738, Standard for calculating the current-temperature relationship of bare overhead conductors, 1993

21 ENA ER P27, Current rating guide for high voltage overhead lines operating in the UK distribution system

22 Neher, J.H., McGrath, M.H. The calculation of the temperature rise and load capability of cable systems. AIEE Transactions, 1957. 76(3) 752-772.

23 IEEE 835, IEEE Standard Power Cable Ampacity Tables, 1994

24 ENA ER P17, Current rating for distribution cables 
25 Susa, D., Lehtonen, M., Nordman, H.,Dynamic thermal modelling of power transformers IEEE Transactions on Power Delivery, 2005. 20(1) 197-204.

26 ANSI/IEEE, C57.92 Guide for loading mineral oil-immersed power transformers up to and including $100 \mathrm{MVA}$ with $55^{\circ} \mathrm{C}$ or $65^{\circ} \mathrm{C}$ average winding rise, 1981

27 ENA ER P15, Transformers loading guide

28 Shepard D., "A two-dimensional interpolation function for irregularly-spaced data", Proceedings of the 1968 23rd ACM national conference, 1968, 517-524

29 IEC 60826 Loading and strength of overhead transmission lines 1991

30 www.metoffice.gov.uk, accessed January 2008

31 Nairen D, Qinyun L, Zhaohong F, Heat transfer in ground heat exchangers with groundwater advection, International Journal of Thermal Sciences, 2004, 43, 1203-1211

32 Nidal H. Abu-Hamdeh, Thermal properties of soil as affected by density and water content, Biosystems engineering, 2003, 86(1), 97-102

33 Celia M, Boulotas E, Zarba R, A general mass-conservative numerical solution for the unsaturated flow problem, Water resources research, 1990, 26(7), 1483-1496

34 Van Genuchten M. A closed for equation for predicting the hydraulic conductivity of unsaturated soils, Soil science society of America Journal, 1980, 44, 892-898

35 I. Rodriguez-Iturbe, V. Isham, D. R. Cox et al, Space-time modelling of soil moisture: stochastic rainfall forcing with heterogeneous vegetation, Water resources research, 200642

36 http://www.sedg.ac.uk/ukgds.htm, accessed January 2008

37 Price, C., Gibbon, R.: Statistical approach to thermal rating of overhead lines for power transmission and distribution, IEE Proceedings, 1983, 130(5), 245-256

38 GE Energy, 3.6 MW Offshore Series Wind Turbine, 2005 


\section{Appendix}

\subsection{Nomenclature}

$A$, conductor cross sectional area $\left[\mathrm{m}^{2}\right]$

$A r$, ageing ratio

$C_{s-T}$, soil thermal capacitance $\left[\mathrm{J} \cdot \mathrm{kg}^{-1} \cdot \mathrm{K}^{-1}\right]$

$D$, external diameter $[\mathrm{m}]$

$d$, internal diameter $[\mathrm{m}]$

$d_{i-k}$, generic locations mutual distance $[\mathrm{m}]$

$E$, Young's modulus of conductor $[\mathrm{Pa}]$

$\mathrm{g}$, gravitation acceleration $\left[\mathrm{m} \cdot \mathrm{s}^{-2}\right]$

$G r$, Grashof number

$H$, tension $[\mathrm{N}]$

$I$, current $[\mathrm{A}]$

$K$, load ratio

$K_{d i r}$, wind direction influence constant

$K_{d i r-1,2,3}$, constants for wind direction factor

$K_{\text {nat-1,2}}$, natural convection coefficients

$K_{\text {shear }}$, ground roughness factor

$k_{s-\theta}$, soil unsaturated hydraulic conductivity $\left[\mathrm{m} \cdot \mathrm{s}^{-1}\right]$

$L$, Span $[\mathrm{m}]$

$l_{r}$, rainfall $[\mathrm{m}]$

$m$, mass per unit length $\left[\mathrm{kg} \cdot \mathrm{m}^{-1}\right]$

$n$, number of conductors in the cable

$N$, sum of sand and clay percentage 
$\mathrm{Nu}$, Nusselt number

$P$, real power flow $[\mathrm{MW}]$

$P r$, prandtl number

$Q$, reactive power flow [MVAr]

$q_{c}$, heat exchanged per unit length by convection $\left[\mathrm{W} \cdot \mathrm{m}^{-1}\right]$

$q_{d}$, dielectric loss per length unit $\left[\mathrm{W} \cdot \mathrm{m}^{-1}\right]$

$q_{r}$, heat exchanged per unit length by irradiation $\left[\mathrm{W} \cdot \mathrm{m}^{-1}\right]$

$q_{s}$, heat gained per unit length by solar radiation $\left[\mathrm{W} \cdot \mathrm{m}^{-1}\right]$

$r$, conductor resistance per length unit $\left[\Omega \cdot \mathrm{m}^{-1}\right]$

$R$, ratio between conductor and core losses

$R e$, Reynolds number

$r_{h o t}$, soil thermal resistivity $\left[\mathrm{m} \cdot \mathrm{K} \cdot \mathrm{W}^{-1}\right]$

$R_{t}$, thermal resistance $\left[\mathrm{m} \cdot \mathrm{K} \cdot \mathrm{W}^{-1}\right]$

$r_{\text {windings }}$, windings resistance $[\Omega]$

$S$, Sag [m]

$T_{a}$, air temperature $[\mathrm{K}]$

$T_{c}$, conductor temperature $[\mathrm{K}]$

$T_{H S}$ hot spot temperature $[\mathrm{K}]$

$T_{s}$, soil temperature $[\mathrm{K}]$

$T_{T O}$, top oil temperature $[\mathrm{K}]$

$V$, Voltage [V]

$w_{d}$, wind-conductor angle [rad]

$W_{s}$, solar radiation $\left[\mathrm{W} \cdot \mathrm{m}^{-2}\right]$

$w_{s}$, wind speed $\left[\mathrm{m} \cdot \mathrm{s}^{-1}\right]$

$x$, oil exponent 
$y$, winding exponent

$z_{b}$, cable burial depth $[\mathrm{m}]$

$Z_{k}$, parameter representing a generic environmental condition

$\alpha$, absorption coefficient

$\beta$, conductor thermal expansion coefficient $\left[\mathrm{K}^{-1}\right]$

$\Delta T$, temperature difference $[\mathrm{K}]$

$\delta_{s-T}$, soil thermal diffusivity $\left[\mathrm{m}^{2} \cdot \mathrm{s}^{-1}\right]$

$\delta_{s-\theta}$, soil unsaturated hydraulic $\left[\mathrm{m}^{2} \cdot \mathrm{s}^{-1}\right]$

$\varepsilon$, emission coefficient

$\lambda$, air thermal conductivity $\left[\mathrm{W} \cdot \mathrm{m}^{-1} \cdot \mathrm{K}^{-1}\right]$

$\lambda_{1,2}$, ratio between metal sheath losses and total losses

$v$, kinematic viscosity $\left[\mathrm{m}^{2} \cdot \mathrm{s}^{-1}\right]$

$\theta$, gravimetric water content $\left[\mathrm{kg} \cdot \mathrm{kg}^{-1}\right]$

$\rho_{s-d e n s i t y}$, dry soil density $\left[\mathrm{kg} \cdot \mathrm{m}^{-3}\right]$

$\rho_{s-T}$, thermal resistivity $\left[\mathrm{m} \cdot \mathrm{K} \cdot \mathrm{W}^{-1}\right]$

$\sigma_{S-B}$, Stephen-Boltzmann constant $\left[\mathrm{W} \cdot \mathrm{m}^{-2} \cdot \mathrm{K}^{-4}\right]$

$\xi_{T}$, electric cables rating temperature correction factor $\left[\mathrm{K}^{-1}\right]$

$\xi_{\rho}$, electric cables rating thermal resistivity correction factor $\left[\mathrm{W} \cdot \mathrm{m}^{-1} \cdot \mathrm{K}^{-1}\right]$ 


\subsection{UKGDS networks}

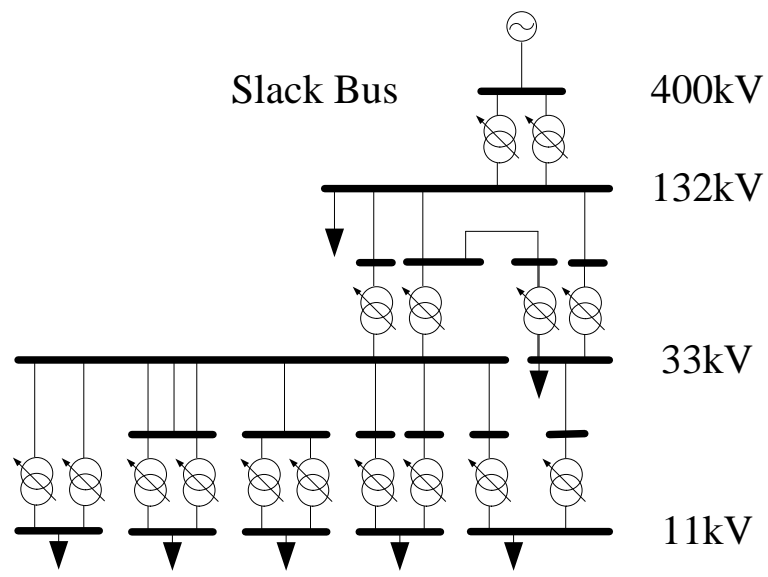

Figure 12: UKGDS A

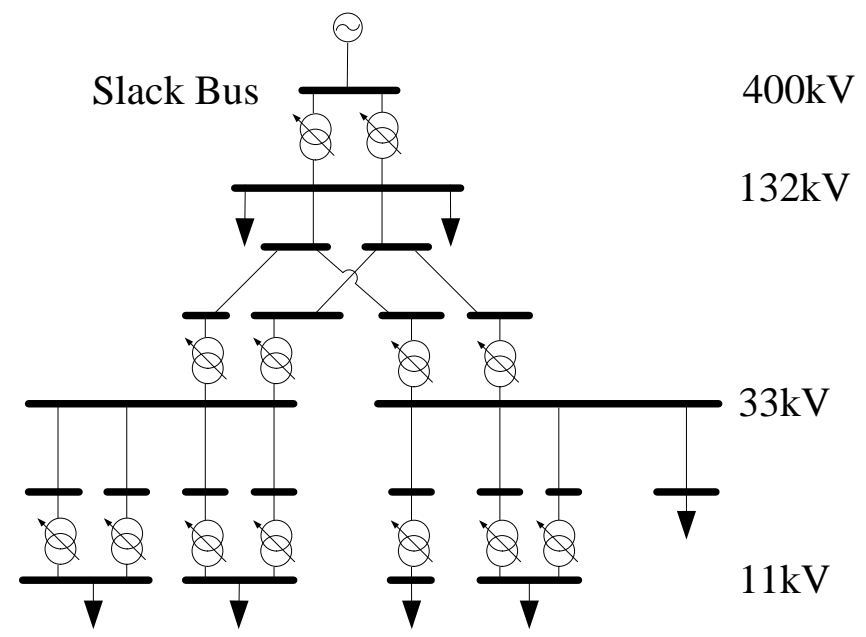

Figure 13: UKGDS B



Figure 14: UKGDS C 


\subsection{Simulation results}

This section provides a summary of the simulation results. For each climate and each network, the average, minimum and maximum calculated ratings are given, along with the static rating and the average annual headroom for each component type. Overhead lines are described with their conductor codes and rated temperature, electric cables with the conductor cross sectional area and power transformers with the cooling method and the rating.

Table 2: Simulation results, component ratings and theoretical headroom

\begin{tabular}{llllll}
\multicolumn{1}{c}{ Component } & $\begin{array}{c}\text { Static } \\
\text { rating } \\
{[\text { [MVA] }}\end{array}$ & $\begin{array}{c}\text { RTR Av. } \\
{[\text { [MVA] }}\end{array}$ & $\begin{array}{c}\text { RTR } \\
\text { Min. } \\
{[\text { MVA] }}\end{array}$ & $\begin{array}{c}\text { RTR } \\
\text { Max. } \\
{[\text { [MVA] }}\end{array}$ & $\begin{array}{c}\text { RTR } \\
\text { Headroom } \\
\text { [GWh/year] }\end{array}$ \\
\hline Overhead line (Lynx 50) & 89 & 213 & 84 & 419 & 988.48 \\
Overhead line (Lynx 65) & 108 & 220 & 94 & 390 & 898.94 \\
Overhead line (Zebra 50) & 154 & 328 & 125 & 595 & 1359.66 \\
Overhead line (Zebra 75) & 206 & 402 & 178 & 731 & 1576.20 \\
\hline Electric cable (150mm ${ }^{2}$ ) & 21 & 21 & 18 & 25 & 2.94 \\
Electric cable (240mm ${ }^{2}$ ) & 30 & 32 & 27 & 37 & 13.33 \\
\hline Power transformer (ODAF 500) & 500 & 532 & 469 & 580 & 282.41 \\
Power transformer (OFAF 240) & 240 & 258 & 223 & 284 & 154.75 \\
Power transformer (ONAN 100) & 100 & 108 & 92 & 120 & 70.80 \\
Power transformer (ONAN 90) & 90 & 97 & 83 & 108 & 63.72 \\
Power transformer (ONAN 60) & 60 & 65 & 55 & 72 & 42.48 \\
Power transformer (ONAN 45) & 45 & 49 & 41 & 54 & 31.87 \\
Power transformer (ONAN 23) & 23 & 25 & 21 & 28 & 16.28 \\
Power transformer (ONAN 21) & 21 & 23 & 19 & 25 & 14.87 \\
Power transformer (ONAN 14) & 14 & 15 & 13 & 17 & 10.80 \\
\hline
\end{tabular}


Table 3: Network components

\begin{tabular}{|c|c|c|}
\hline Network & Component & $\mathbf{N}$ \\
\hline SITE & Overhead line (Lynx 50) & 11 \\
\hline SITE & Electric cable $\left(150 \mathrm{~mm}^{2}\right)$ & 11 \\
\hline SITE & Power transformer (OFAF 240) & 5 \\
\hline SITE & Power transformer (ONAN 45) & 5 \\
\hline SITE & Power transformer (ONAN 60) & 2 \\
\hline SITE & Power transformer (ONAN 90) & 1 \\
\hline UKGDS_A & Overhead line (Lynx 50) & 1 \\
\hline UKGDS_A & Overhead line (Lynx 65) & 3 \\
\hline UKGDS_A & Overhead line (Zebra 75) & 2 \\
\hline UKGDS_A & Electric cable $\left(150 \mathrm{~mm}^{2}\right)$ & 4 \\
\hline UKGDS_A & Electric cable $\left(240 \mathrm{~mm}^{2}\right)$ & 10 \\
\hline UKGDS_A & Power transformer (ODAF 500) & 1 \\
\hline UKGDS_A & Power transformer (ONAN 23) & 1 \\
\hline UKGDS_A & Power transformer (ONAN 60) & 6 \\
\hline UKGDS_A & Power transformer (ONAN 90) & 2 \\
\hline UKGDS_A & Power transformer (ONAN 14) & 2 \\
\hline UKGDS_B & Overhead line (Lynx 65) & 4 \\
\hline UKGDS_B & Overhead line (Zebra 75) & 2 \\
\hline UKGDS_B & Electric cable $\left(150 \mathrm{~mm}^{2}\right)$ & 7 \\
\hline UKGDS_B & Electric cable $\left(240 \mathrm{~mm}^{2}\right)$ & 1 \\
\hline UKGDS_B & Power transformer (ODAF 500) & 2 \\
\hline UKGDS_B & Power transformer (ONAN 100) & 1 \\
\hline UKGDS_B & Power transformer (ONAN 21) & 2 \\
\hline UKGDS_B & Power transformer (ONAN 23) & 5 \\
\hline UKGDS_B & Power transformer (ONAN 45) & 2 \\
\hline UKGDS_B & Power transformer (ONAN 90) & 1 \\
\hline UKGDS_C & Overhead line (Zebra 50) & 2 \\
\hline UKGDS_C & Electric cable $\left(150 \mathrm{~mm}^{2}\right)$ & 1 \\
\hline UKGDS_C & Electric cable $\left(240 \mathrm{~mm}^{2}\right)$ & 9 \\
\hline UKGDS_C & Power transformer (ODAF 500) & 1 \\
\hline UKGDS_C & Power transformer (ONAN 60) & 1 \\
\hline UKGDS_C & Power transformer (ONAN 14) & 1 \\
\hline UKGDS_C & Power transformer (ONAN 23) & 10 \\
\hline UKGDS_C & Power transformer (ONAN 60) & 1 \\
\hline UKGDS_C & Power transformer (ONAN 14) & 2 \\
\hline UKGDS_C & Power transformer (ONAN 23) & 1 \\
\hline
\end{tabular}




\section{Text Tables and Figures}

Table 1: Simulation results for SITE network components exposed to the Valley climatic scenario.

\begin{tabular}{lrrrrr}
\multicolumn{1}{c}{ Component } & $\begin{array}{c}\text { Static } \\
\text { rating } \\
\text { [MVA] }\end{array}$ & $\begin{array}{c}\text { RTR Average } \\
\text { [MVA] }\end{array}$ & $\begin{array}{c}\text { RTR Min } \\
\text { [MVA] }\end{array}$ & $\begin{array}{c}\text { RTR Max } \\
\text { [MVA] }\end{array}$ & $\begin{array}{c}\text { Additional } \\
\text { RTR headroom } \\
\text { [GWh/year] }\end{array}$ \\
\hline Electric cable (150mm2) & 21 & 21 & 19 & 23 & 1.83 \\
Power transformer (ONAN 45) & 45 & 48 & 44 & 52 & 30.7 \\
Power transformer (OFAN 240) & 240 & 257 & 235 & 276 & 149.1 \\
Overhead line (Lynx 50) & 89 & 253 & 107 & 419 & 1342
\end{tabular}

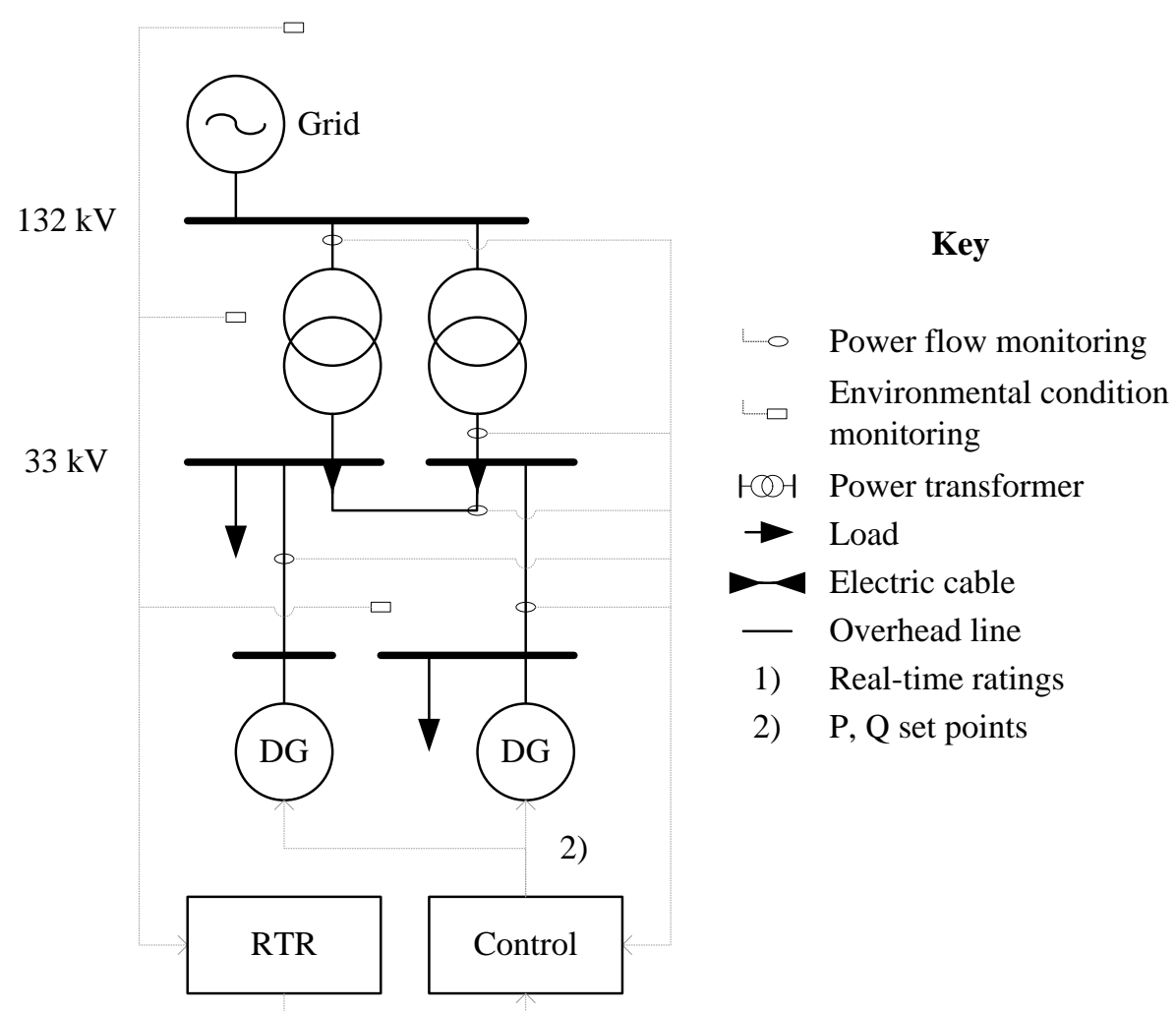

1)

Figure 1: DG power output controller informed by RTRs 


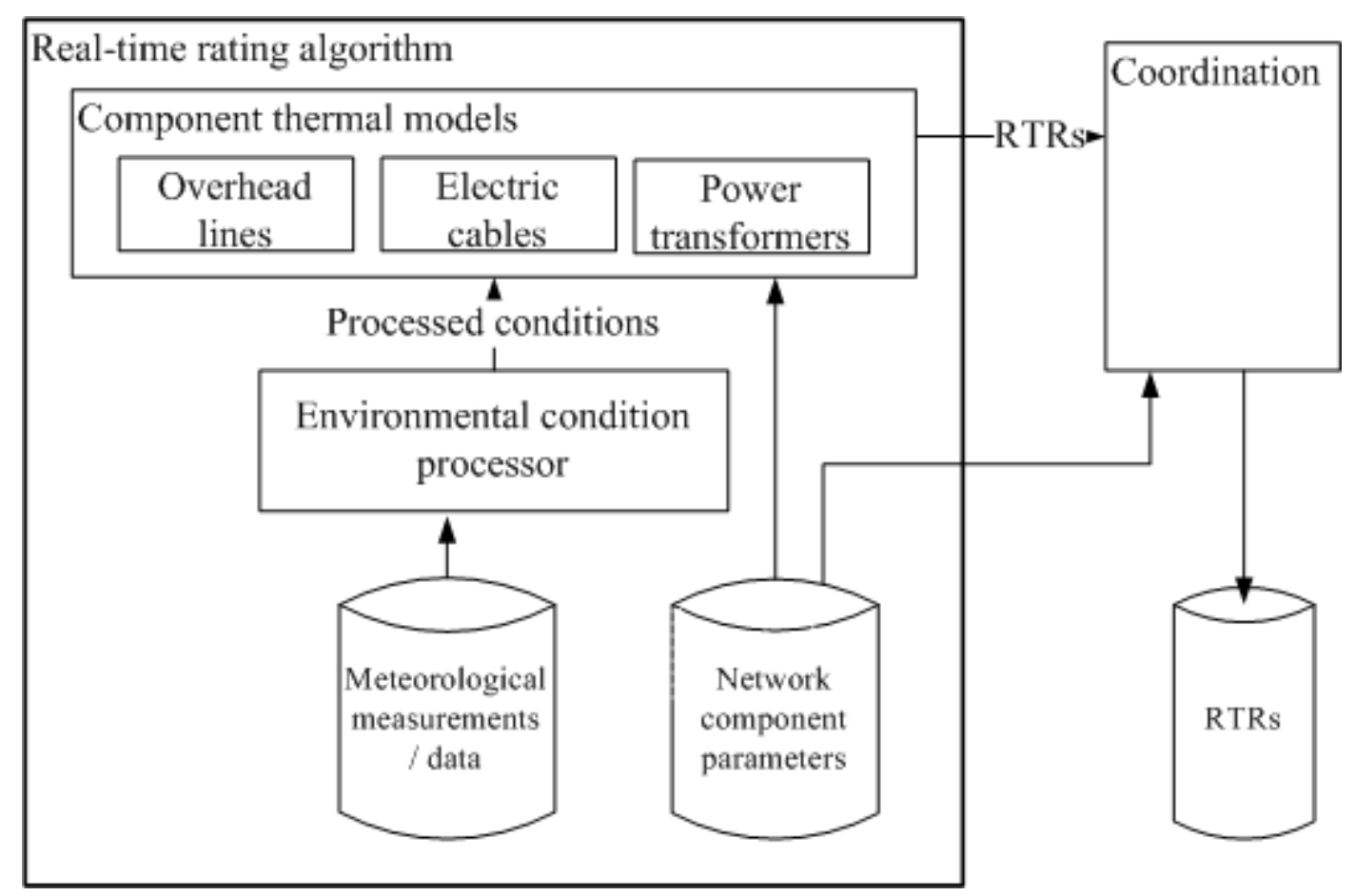

Figure 2: Simulation scheme

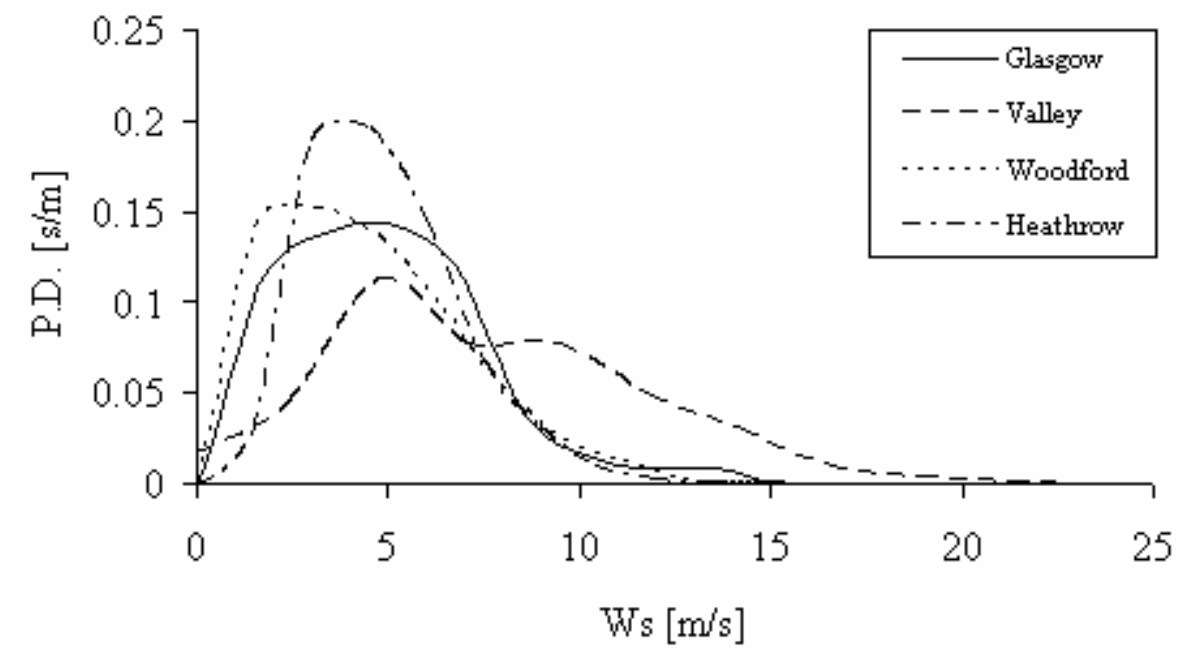

Figure 3: Wind speed probability distribution 


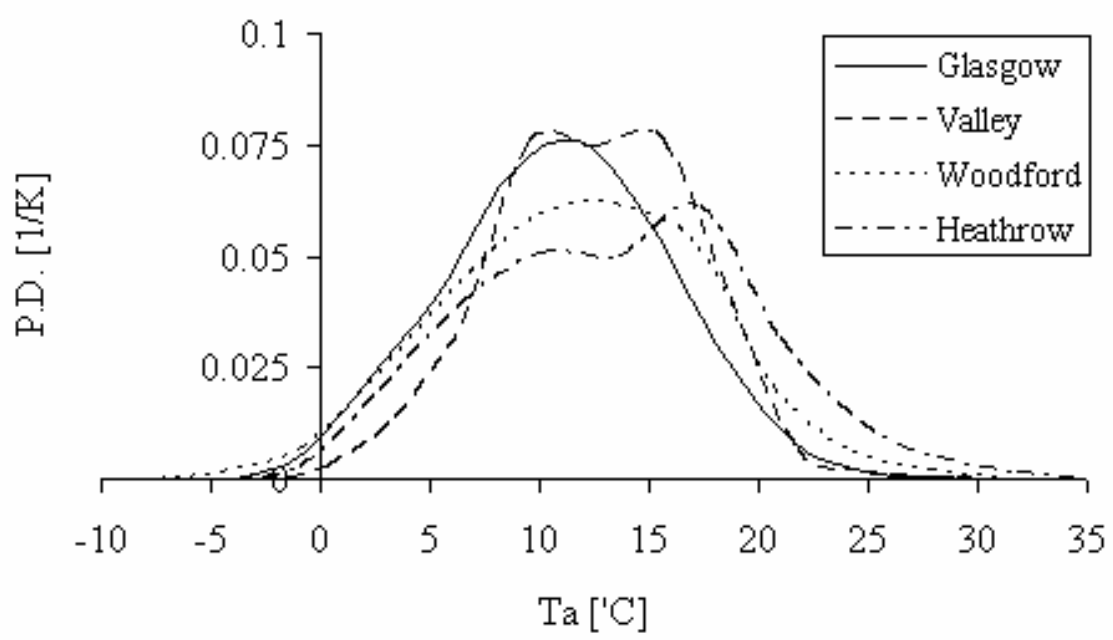

Figure 4: Air temperature probability distribution

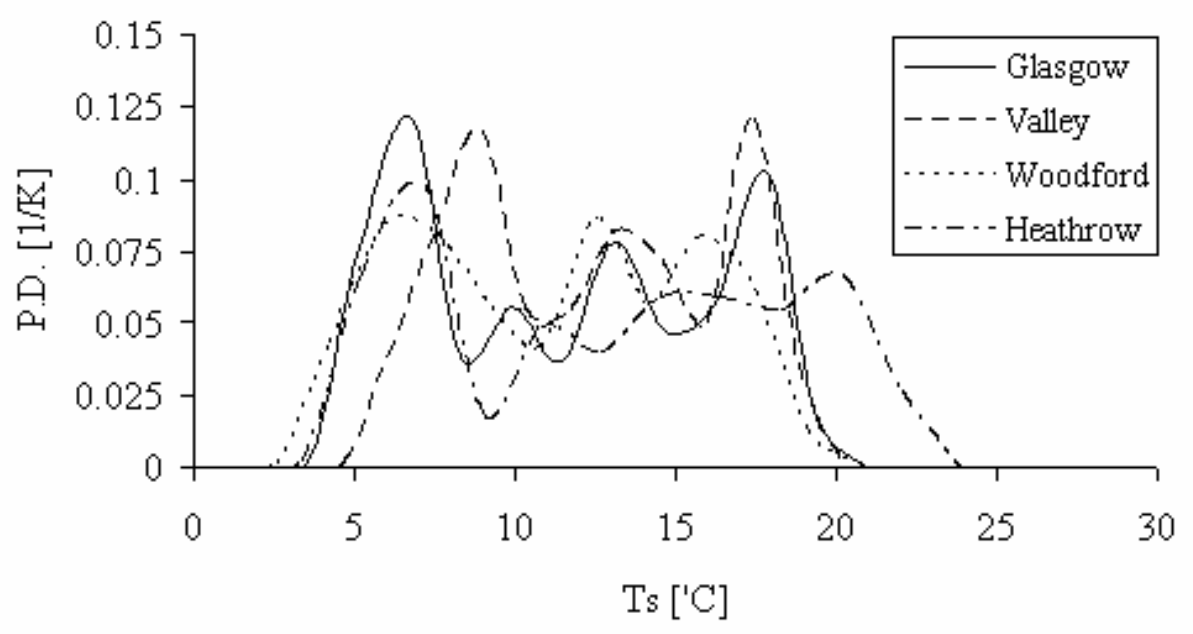

Figure 5: Soil temperature probability distribution

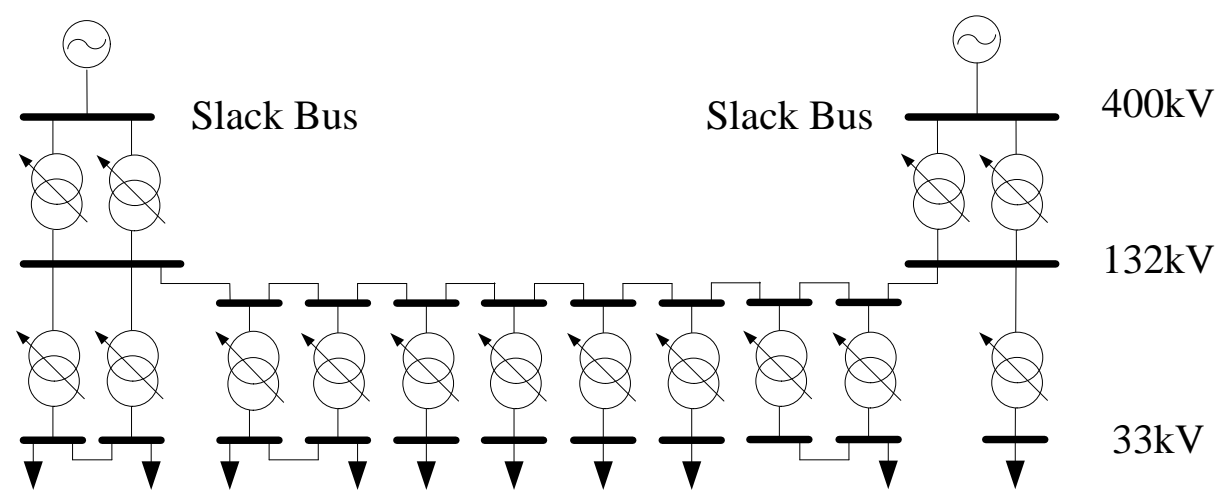

Figure 6: Site trial 


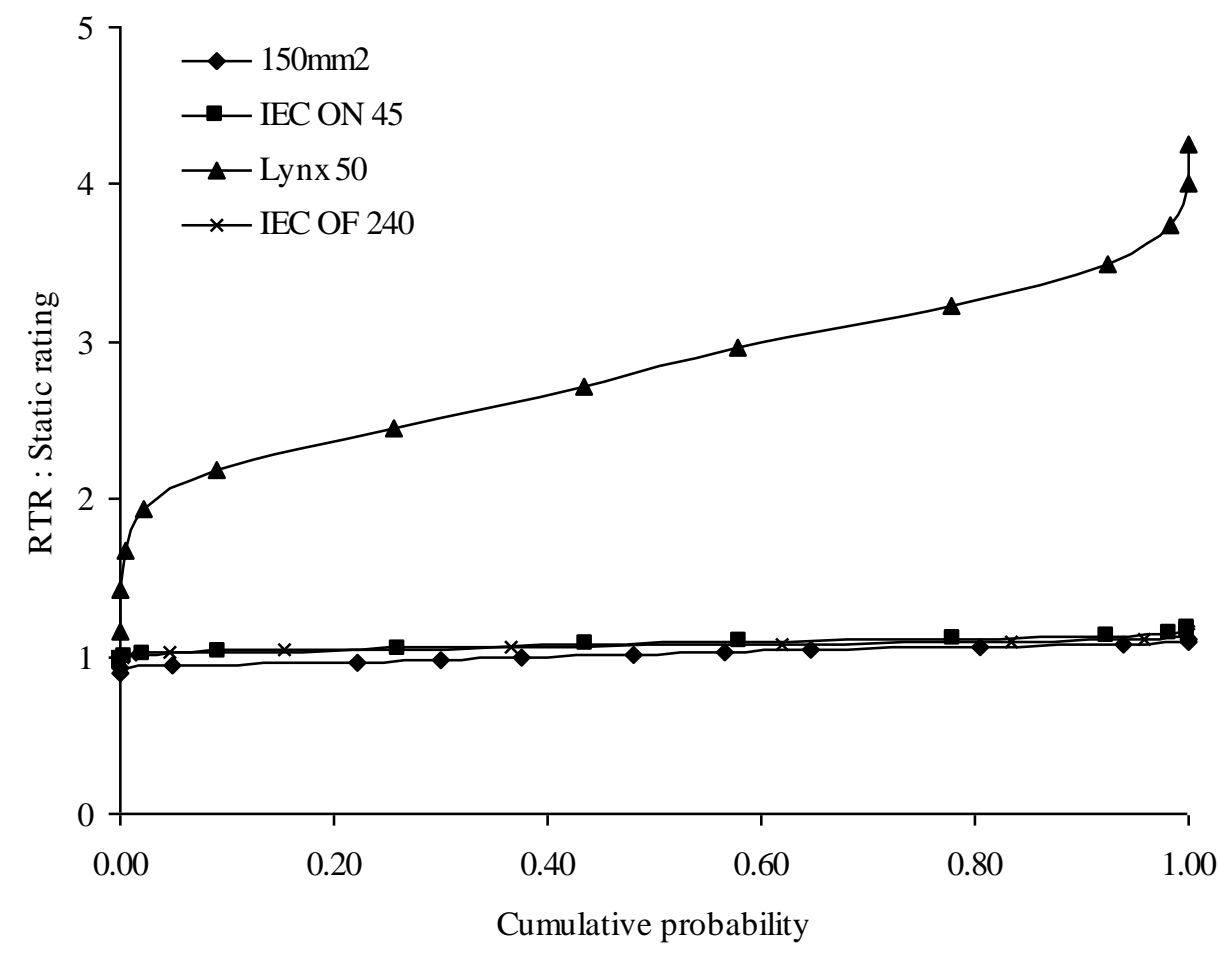

Figure 7 a): Rating cumulative probability for SITE network components exposed to the Valley climatic scenario

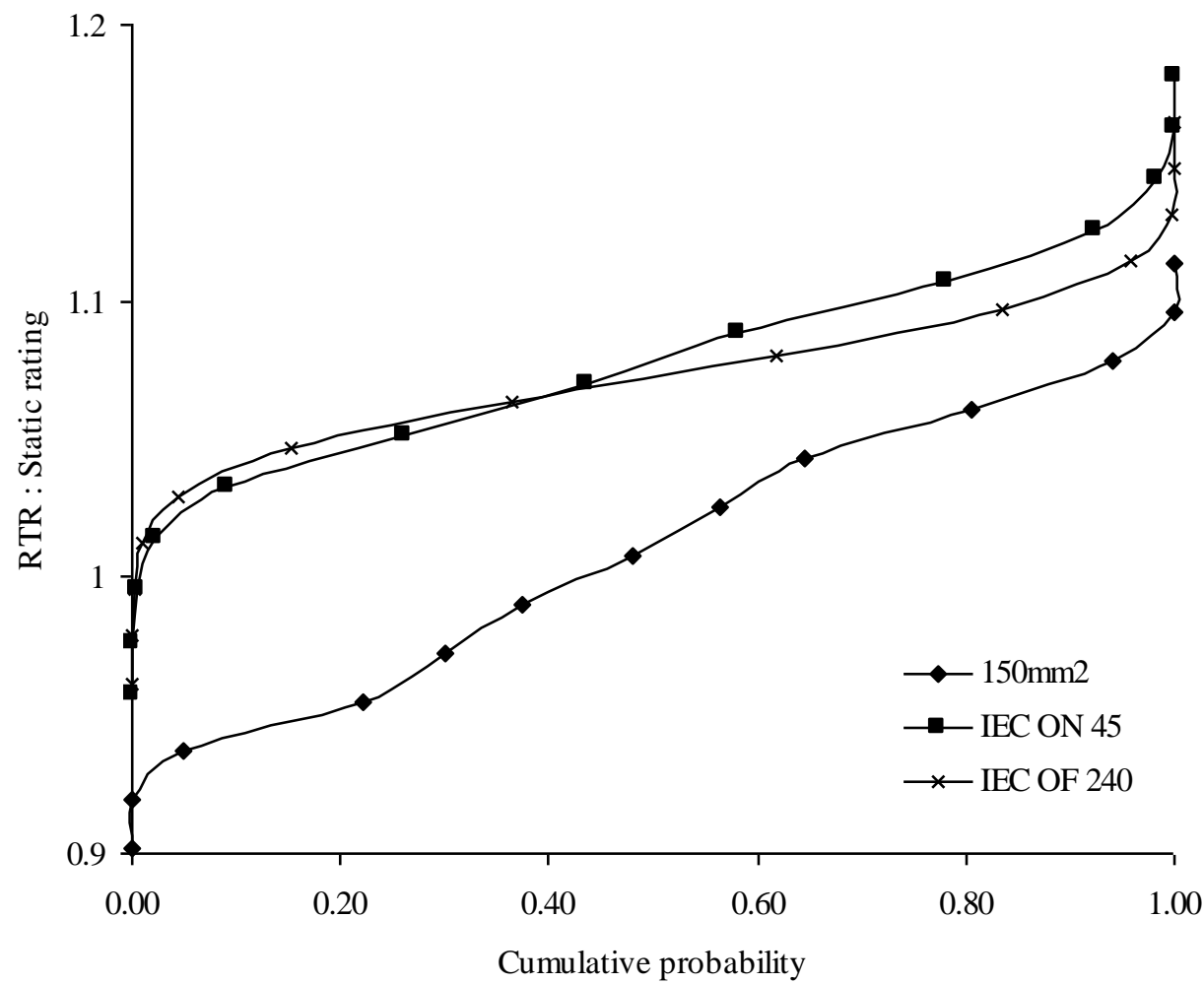

Figure 7 b): Magnified rating cumulative probability for SITE network components exposed to the Valley climatic scenario 


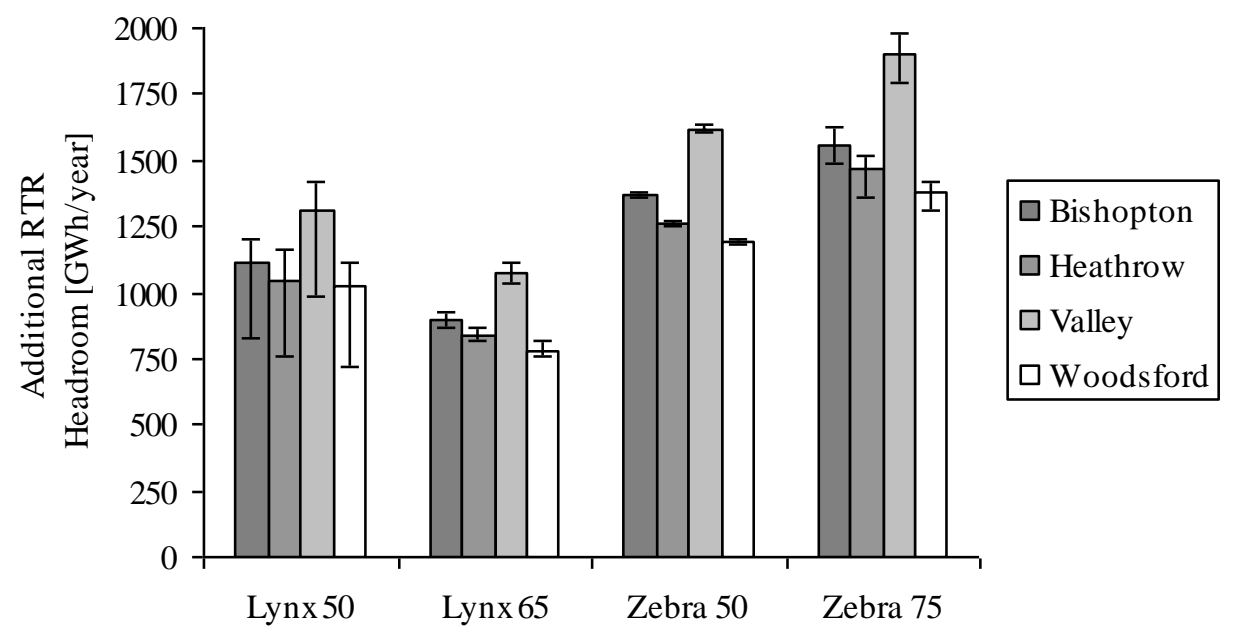

Figure 8: Influence of different UK climates on overhead lines power transfer headroom

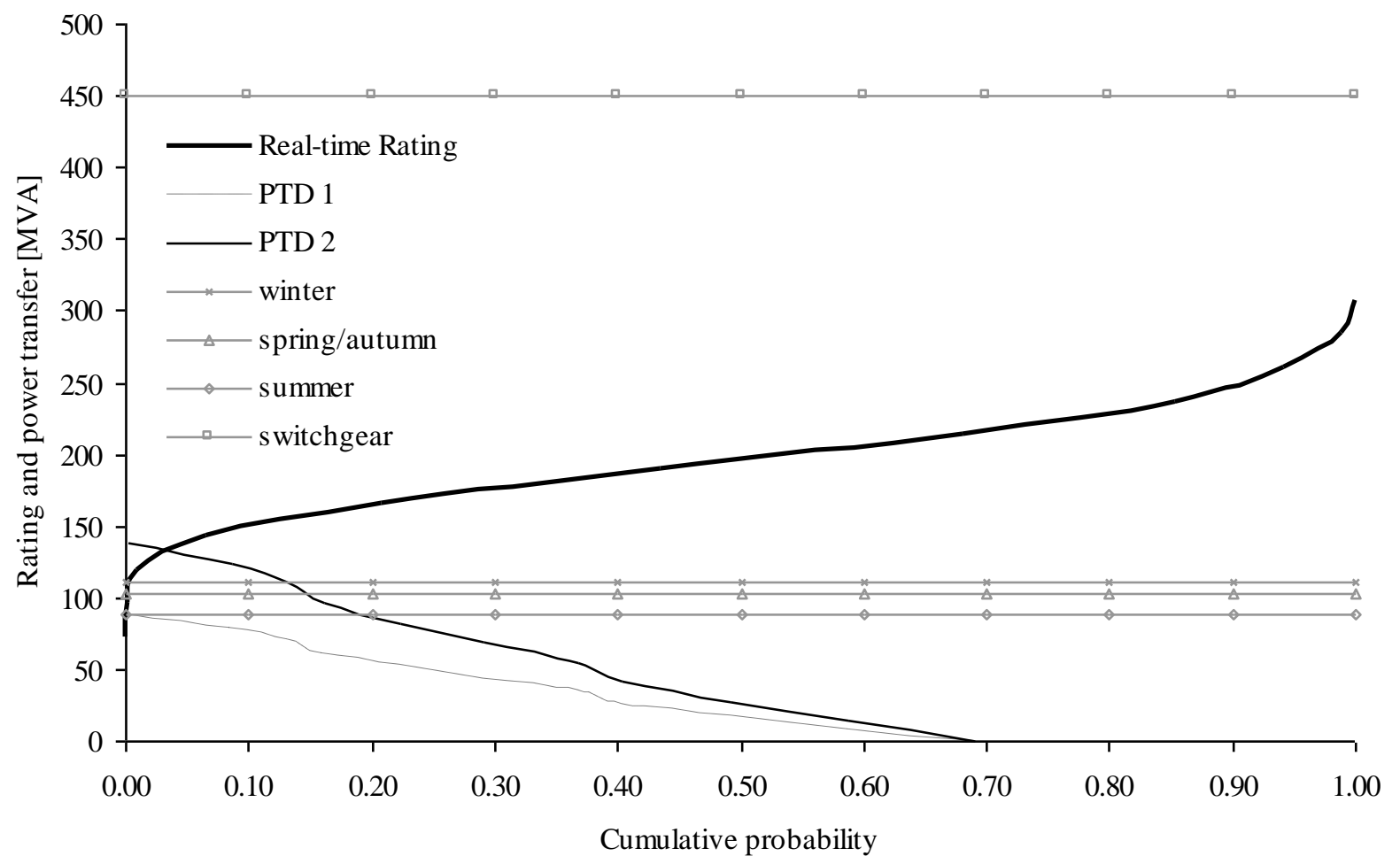

Figure 9: Cumulative probability comparison for a Lynx conductor in the Valley scenario 